\title{
Clinical Profile of Ocular Diseases at a Tertiary Eye Care Centre in Mid- Western Nepal
}

\author{
Pragya Singh Basnet ${ }^{1}$, Sagun Malla ${ }^{1}$, Deepa Sharma', Roshan Gautam ${ }^{1}$
}

${ }^{1}$ Department of Ophthalmology, Rapti Academy of Health Sciences, Dang, Nepal

${ }^{2}$ Department of Research, Rapti Academy of Health Sciences, Dang, Nepal

\section{ABSTRACT}

Introduction: Nepal is a developing country where most of the population does not have access to proper health care services and on top of that eye care services do not reach the entire population. This study aimed to determine the pattern of ocular morbidity in patients attending the ophthalmic Out Patient Department of Rapti Academy of Health Sciences.

Materials and Methods: This was a prospective cross-sectional study conducted in the Department of Ophthalmology of Rapti Academy of Health Science, Dang. The study period was Poush 2077 to Chaitra 2077. All the patients visiting the Out Patient Department of the Ophthalmology department with an ocular problem were included in the study.

Results: A total of 1000 patients were examined during the study period. The patient's ages below 1 year were excluded so a total of 970 samples was selected. In which $625(64.4 \%)$ were female and 345 (35.6\%) were male. Most patients $92.9 \%$ were from Dang followed by Rolpa $4.1 \%$, Rukum $1.4 \%$, Pyuthan $0.9 \%$, and Salyan $0.6 \%$. Patients were examined from all age groups except for 1 year which was excluded. Out of the total patients, a maximum number of patients were female and the maximum number of patients were in the age group of 21-30 years and followed by more than or equal to 60 years age group.

Conclusions: This study will help in obtaining epidemiology of Ocular disease for proper planning and management in the hospital.

Keywords: Cataract; Conjunctivitis; Ophthalmic disease; Rural area

\section{Correspondence:}

Dr. Pragya Singh Basnet, MD

Rapti Academy of Health Sciences, Dang, Nepal ORCID ID: 0000-0001-7698-2352

Email:pragyabasnet79@gmail.com

Submitted: $5^{\text {th }}$ June 2021 Accepted: $28^{\text {th }}$ June 2021

Source of Support: None

Conflict of Interest: No

Citation: Basnet PS, Malla S, Sharma D, Gautam R. Clinical Profile of Ocular Diseases at a Tertiary Eye Care Centre in Mid-Western Nepal. NMJ 2021;4(1):43941. DOI $10.3126 /$ nmj.v4i1.37847

\section{INTRODUCTION}

Nepal is a developing country where most of the population does not have access to proper health care services and on top of that eye care services do not reach the entire population. The study will be one of the first studies to be conducted to explore the profile of ocular diseases at a tertiary care center in Dang Valley.
The pattern of blindness and visual impairment varies with age with geographic and socioeconomic conditions. According to Nepal blindness survey prevalence of blindness is $0.84 \%$ and cataract is the most common cause of preventable blindness accounting for our $78 \%$ of cases. ${ }^{1}$ The best option to reduce ocular morbidity is to bring eye care services to their doorsteps in 
the form of outreach programs. The result of the 1981 blindness survey led to the establishment of a national eye care program for control and prevention of blindness in Nepal which showed that $0.84 \%$ of the Nepalese population was bilaterally blind. ${ }^{2}$

Optimum management of Ocular disease has a large impact on the prevention of visual loss in patients suffering from eye problems. Appropriate treatment of these patients reduces the burden of ocular health problems.

The establishment of an eye care delivery system for the treatment of eye disease and prevention of blindness is linked to the existing general services and resources available. ${ }^{3}$ The study which we conducted aims to find out the different patterns of ocular morbidity in the existing community as there are not much data regarding the pattern of diseases that could keep our plan and provide adequate health care services and manage the diseases.

\section{MATERIALS AND METHODS}

This was a prospective analysis of a cross-sectional study conducted in the Department of Ophthalmology from Poush to Chaitra 2077. Ethical consideration was taken from the IRC(11, 2077/2078) of Rapti Academy of Health Science. All the patient's records attending the OPD of RAHS were included in the study. Patients less than 1 year of age were excluded from the study.

Data collection was done from the patient register maintained in OPD which included name, gender, diagnosis, and treatment. All the patients were examined by a consultant Ophthalmologist and refection was performed by Optometrist and prescribed accordingly. The patients underwent a thorough routine eye examination which included Distant - V A by Snellen's chart both. Uncorrected and best-connected VA including near vision, Tonometry, Slit Lamp Examination of the anterior segment and further evaluation of posterior segment using 90D, 20D, and color vision testing done by Ischiharas Isochromatic chart. Data were entered in Excel and analyzed in SPSS software vs. 17.

\section{RESULTS}

A total of 1000 patients were examined since Poush - Chaitra. The patient's ages below 1 year were excluded so a total of 970 samples was selected. In which $625(64.4 \%)$ were female and $345(35.6 \%)$ were male. Most patients $92.9 \%$ were from Dang followed by Rolpa $4.1 \%$ and Rukum $1.4 \%$. The mean age was $38.01 \pm 21.16$ years. The maximum number of the patient were females and the maximum number of patients were in the age group of 21-30 years followed by $\geq 60$ years, age group. (Table 1 )

Table 1: Age and gender-wise distribution of patients attending the OPD

\begin{tabular}{llll}
\hline & & \multicolumn{2}{c}{ Gender } \\
& & Female n (\%) & Male n (\%) \\
\hline Age Groups (in Years) & $2-10$ & $29(4.6 \%)$ & $48(13.9 \%)$ \\
& $11-20$ & $109(17.4 \%)$ & $48(13.9 \%)$ \\
& $21-30$ & $124(19.8 \%)$ & $53(15.4 \%)$ \\
& $31-40$ & $112(17.9 \%)$ & $46(13.3 \%)$ \\
& $41-50$ & $90(14.4 \%)$ & $42(12.2 \%)$ \\
& $51-60$ & $57(9.1 \%)$ & $40(11.6 \%)$ \\
& $\geq 60$ & $104(16.6 \%)$ & $68(19.7 \%)$ \\
\hline Total & & $625(64.4 \%)$ & $345(35.6 \%)$ \\
\hline
\end{tabular}

The mean age was $38.01 \pm 21.16$ and the above table shows that the maximum number of patients were in the age group of 21-30 years followed by $\geq 60$ years age group.

Table 2 depicts the various ocular diseases among the study population. Age-Related Cataract was the most common ocular morbidity accounting for $144(14.8 \%)$ cases followed by Dry Eye Syndrome 125 (12.9\%), Ocular Allergy (9.9\%) cases. It was observed that Ocular allergy, Conjunctivitis, and Refractive Error were more seen in younger age while Cataract was more prevalent in the older age i.e. more than 60 years of age

Table 2: Frequency of ocular diseases among the study population

\begin{tabular}{|c|c|c|c|}
\hline $\begin{array}{l}\text { Ocular } \\
\text { Diseases }\end{array}$ & $\begin{array}{l}\text { Frequency and } \\
\text { Percentage } \mathrm{n}(\%)\end{array}$ & $\begin{array}{l}\text { Ocular } \\
\text { Diseases }\end{array}$ & $\begin{array}{l}\text { Frequency and } \\
\text { Percentage } n \\
(\%)\end{array}$ \\
\hline $\begin{array}{l}\text { Age Related } \\
\text { Cataract }\end{array}$ & $144(14.8 \%)$ & $\begin{array}{l}\text { Sub } \\
\text { conjunctival } \\
\text { Hemorrhage }\end{array}$ & $34(3.5 \%)$ \\
\hline $\begin{array}{l}\text { Dry Eye } \\
\text { Syndrome }\end{array}$ & $125(12.9 \%)$ & Asthenopia & $20(2.1 \%)$ \\
\hline Ocular Allergy & $96(9.9 \%)$ & Pingueculitis & $17(1.8 \%)$ \\
\hline $\begin{array}{l}\text { Refractive } \\
\text { Error }\end{array}$ & $91(9.4 \%)$ & Keratitis & $16(1.6 \%)$ \\
\hline Conjunctivitis & $79(8.1)$ & $\begin{array}{l}\text { Ocular } \\
\text { Trauma }\end{array}$ & $14(1.4 \%)$ \\
\hline Presbyopia & $71(7.3 \%)$ & Others & $171(17.6 \%)$ \\
\hline Pseudophakia & $70(7.2 \%)$ & & \\
\hline
\end{tabular}

\section{DISCUSSION}

In this study, the most common age group for ocular morbidity was between $21-30$ years, followed by $\geq 60$ years, age group. A study conducted by Tuladhar $\mathrm{S}^{4}$ about the pattern of ocular morbidity of patients attending a clinic in western Nepal showed that out of 915 patients, most of the people were between age group 11-20 years followed by the second common in the age group 21-30 years which was similar to our study.

Another study by Mitali G Patel ${ }^{5}$ et all done in a tertiary care hospital in Gujrat showed the prevalence of ocular morbidities was increasing with age more than 60 years age group was $30.76 \%$ followed by $51-60$ age group was $22 \%$. Our study shows that $64.4 \%$ were female whereas $35.6 \%$ was male which proves female preponderance in our study which is similar to the study by Tuladhar et al and Sochin Dhakal ${ }^{4}$ as well as similar results was found in National Blindness Survey ${ }^{2}$ where the survey took place at rural areas thereby enabling the female for easy access to eye care services. Similar results were found by a study performed by Sherchen ${ }^{6}$ et al in the Chitwan district of Nepal where there was $52 \%$ female in the total enumerated population.

Regarding the most common ocular morbidity, this study showed that the most common ocular disease was Age-related Cataract accounting for $14.8 \%$ followed by Dry Eye syndrome $(12.9 \%)$ Ocular Allergy 9.9\%, and Refractive Error 9.4\%. Conjunctivitis is comprised of all forms of conjunctivitis to be $8.1 \%$ followed by Pseudophakia 7.2\%. It was observed that Ocular Allergy, Conjunctivitis, and Refractive Error were more seen at a younger age. But a similar study by Tuladhar et al showed that Refractive 
Error was the most common ocular morbidity followed by Cataracts. $^{4}$

A study done in Combodia by Ian Thomson ${ }^{7}$ showed a male to female ratio of $2: 3$ where the most common ocular mortality was mature cataract responsible for $61 \%$ of blindness followed by chronic Glaucoma. Similar to our study a cross-sectional study conducted in an OPD of Ophthalmology at a tertiary care hospital in India by M. Lipa ${ }^{8}$ showed out of 600 patients, the majority of patients were in the 30-60 age group and there was no sex preponderance as male to female ratio was $1.2 \%$.

A study conducted by UN hospital ${ }^{9}$ showed that the three most common causes of eye disorder were Refractive Error, followed by Allergic conjunctivitis, and Presbyopia, and the most common age group was 30-44 years (35.4\%).
Many different ophthalmic diseases can be discovered through efficient screening systems. A developing country like ours usually lacks effective screening programs. The knowledge of disease profiles helps Ophthalmologist enforce preventive measures and prepare treatment.

\section{CONCLUSIONS}

Ocular morbidities had seen more in females than males and AgeRelated Cataracts, Dry Eye Syndrome, Ocular Allergy, Refractive Error were the most common ocular morbidity. Knowledge of these common ocular morbidities helps in adequate and appropriate prophylactic measures to prevent such conditions.

\section{REFERENCES}

1. Pokharel GP, Regmi G, Shrestha SK, A D Negrel, L B Ellwein. Prevalence of blindness and Cataract surgery in Nepal. British Journal of Ophthalmology. 1998;82(6):600-5. Crossref

2. Brilliant LB, Pokhrel RP, Grasset NC, JM Lepkowski, A Kolstad, W Hawks, R Pararajasegaram et al. Epidemiology of blindness in Nepal. Bulletin of the World Health Organization. 1985;63(2):375. Website

3. Sihota R, Parsons R . Parsons Diseases of Eye. 20th ed. Elsevier. Reed Elsevier India Private Limited, India. 2007. 641p.

4. Tuladhar S, Dhakal S. A Pattern of Ocular Morbidity in Patients Attending Anophtalmic Clinic in a Rural Part of Western Nepal. Journal of Nobel Medical College. 2013;2(1):27-30. Website

5. Patel M, Mahyavanshi D, Nayak S et all. Pattern of ocular morbidity in patients attending ophthalmic OPD at tertiary care hospital, Valsad, Gujarat. International Journal of Community Medicine And Public Health. 2018;5(2):569-73. Crossref
6. Sherchan A, Kandel RP, Sharma MK. Blindness prevalence and cataract surgery in Gandaki zone, Nepal. British journal of ophthalmology. 2006;90(2):411-6. Crossref

7. Thomson I. A clinic based survey of blindness and eye disease in Cambodia. British journal of Ophthalmology. 1997; 81(7):578-80. Crossref

8. Lipa M, Banu TJ. A cross-sectional study to assess the morbidity pattern of ocular diseases in outpatient department of ophthalmology at a tertiary care hospital. International Journal of Research in Medical Sciences. 2016; 4(9):3797-800. Website

9. Baranwal VK, Mishra A, Sharma V, Gupta S, Sundar S, Verma S. Eye Diseases among Patients of Different Nationalities attending the Ophthalmology Clinic. The Prevalence of Various Eye Diseases Among Patients of Different Nationalities attending the Ophthalmology Clinic at a Tertiary Care United Nations Hospital: A 5 Year Retrospective Analysis. 2019;6(9). Website 